\title{
ECG-based detection of left ventricle hypertrophy
}

Gabriel Tozatto Zago*, Rodrigo Varejão Andreão, Sérgio Lamego Rodrigues, José Geraldo Mill, Mário Sarcinelli Filho

\begin{abstract}
Introduction: Left ventricle hypertrophy (LVH) is an important risk factor for cardiovascular morbidity and mortality. It is characterized by a thickening of the walls of the left ventricle. The transthoracic echocardiogram is a very accurate method for $\mathrm{LVH}$ detection. However, the electrocardiogram (ECG) offers an alternative method in diagnosing $\mathrm{LVH}$, besides being less expensive and easier to obtain. In this context, this study proposes an ECG based approach for left ventricle hypertrophy (LVH) classification. Methods: According to the literature, several indexes have so far been proposed that suggest specific changes in cardiac structure, however, generally speaking there is no consensus about the best criteria. This way, instead of considering only one LVH criterion, a score derived from electrocardiographic traces was employed which explores the complementarity of the best criteria through a fusion strategy. The best criteria are those which discriminate normal and LVH ECGs. Results: The experiments were performed in the Monica database with a group of fifty men. Half of the individuals had LVH diagnosed by calculating the left ventricular mass index measured by transthoracic echocardiography. The score fusion proposed achieved a sensitivity of $78.3 \%$ and specificity of $91.3 \%$, outperforming all isolated LVH criteria. Discussion: Unlike the other methods, our score must be estimated within a computer because of its high complexity. Even with this limitation it is much less expensive than using the echocardiography.
\end{abstract}

Keywords: Left ventricle hypertrophy, Electrocardiogram, Score fusion.

\section{Introduction}

Left ventricle hypertrophy (LVH) is an important risk factor for cardiovascular morbidity and mortality, including sudden death (Haider et al., 1998; Kreger et al., 1987). LVH can be caused by several cardiovascular diseases, such as arterial hypertension, increased blood viscosity, heart failure and cardiomyopathies. LVH can be also found in non-pathological conditions, such as in subjects submitted to long term aerobic or resistive exercise.

Hypertension is a highly prevalent condition in the adult population and is characterized by chronically elevated blood pressure levels followed by structural and functional adaptations of the heart to the work load, thereby leading to an increase in the left ventricle (LV) mass (Ganau et al., 1992). This mass increase can be detected and quantified by several cardiac imaging procedures. The transthoracic echocardiogram has been the most used imaging method for this purpose and has been considered the gold standard method for measuring LV mass in clinical conditions. Cardiac mass interferes on the generation and propagation of electrical signals in the heart. Therefore, the conventional 12-lead ECG has been used to indirectly assess the LV mass and to detect the presence of LVH. However, the ECG only allows qualitative LVH analysis, suggesting the presence or the absence of LVH in a specific individual. In spite of this limitation, ECG is still the most used exam to assess changes in cardiac structure because it is easy to perform, noninvasive and relatively inexpensive. In primary health care services, the ECG is still the only exam that is used to evaluate the presence of $\mathrm{LVH}$ and is generally used before the echocardiogram exploration of cardiac structure and function.

Many criteria have been used to obtain ECG-based LVH diagnosis. QRS amplitude and duration have been the most widely used (Hancock et al., 2009; Mazzaro et al., 2008), since the QRS complex reflects ventricular depolarization. However, there is no agreement about which criteria would be more reliable, and therefore, which should be used.

The introduction of digital apparatus to record ECG facilitates the test of several indexes that might indicate specific changes in cardiac structure. In this context, the aim of this study is to explore the correlations between the electrocardiographic indexes and LVH. In order to explore the complementarity of the criteria proposed so far (Hancock et al., 2009; Mazzaro et al., 2008), an original score is proposed based on the combination of the results of the best 
criteria. The criteria were implemented and tested in a database containing ECG exams from individuals submitted to a standard echocardiogram. Both the echocardiogram and the ECG were obtained under similar conditions during a research project whose objective was to determine the cardiovascular risk factors in the general population (Angelo et al., 2007; Pires de Sousa et al., 2009).

\section{Methods}

\section{Left ventricle hypertrophy}

LVH is characterized by the thickening of the walls of the LV. The main exam for LVH detection is the echocardiogram, which uses ultrasound waves to measure the thickness of the heart wall and chamber diameters. The LV mass is then calculated by approximating the geometry and density of this chamber using the formula proposed by Devereux et al. (1986). However, the cardiac size, and thus LV mass, varies depending on the height of the patient. Therefore, the LV mass could indicate $\mathrm{LVH}$ for a $1.60 \mathrm{~m}$ tall patient, but not for a $1.90 \mathrm{~m}$ one. As a consequence, the LV mass is indexed (LVMI) by height, i.e.,

$$
L V M I=\frac{L V M}{h^{2.7}}
$$

where LVM is the LV mass in grams and $h$ is the height of the patient in meters (De Simone et al., 2005).

The ECG is another exam used for $\mathrm{LVH}$ detection. In addition to being ineffective for detecting anatomic $\mathrm{LVH}$ and limited for obtaining a quantitative measurement of LV mass, the ECG can only be used to qualitatively infer the presence of a LV mass increase. Plenty of methods have been used by physicians to detect LVH by means of the ECG. Most of them are based on the amplitude and width of the QRS complex (Hancock et al., 2009). However, there is no agreement among experts regarding which method is the most reliable because it is impossible to maintain specificity (rate of normal patients correctly classified) and sensitivity (rate of LVH patients correctly classified) high at the same time. It is noteworthy that when classifying most of the LVH patients correctly, some normal patients will also be classified as having LVH, and vice-versa.

In order to find out the best criteria to detect LVH through the ECG is, several criteria were tested, some of them already proposed in the literature and others originally proposed in this paper, as follows:

- The peak amplitude of the QRS and T waves in all 12 leads.
- The duration of several intervals in the ECG in all 12 leads.

- The area of the QRS complex and some intervals in the ECG.

- The angle of the electric axis during ventricular activation.

- The presence of the strain pattern (Roman et al., 1987).

The main criteria tested in this work are described in Hancock et al. (2009) and the ones that achieved the best results are explained later in Table 1.

\section{ECG processing}

In order to build a fully automatic method to detect $\mathrm{LVH}$, the following steps are required:

- ECG segmentation;

- ECG feature extraction;

- LVH patient classification.

The first step is based on an automatic segmentation algorithm of the 12 lead ECG. In this study, the segmentation provides the following ECG features:

- the onset, peak and end of the QRS complex;

- the peak and end of the T wave.

The key point in the segmentation of the ECG is the identification of peaks or valleys of the QRS complex. All other points are based on the QRS peak. Our QRS peak detection algorithm is based on Hamilton (2002), it combines filtering and heuristic rules to detect this key point. The filtering step is divided in three parts: a pass-band filter (from 8 to $16 \mathrm{~Hz}$ ), a first derivative filter and a moving average filter $(80 \mathrm{~ms})$. The following steps are applied to the filtered signal. A maximum is considered a peak when its amplitude is greater than $30 \%$ of the mean value of the last eight detected peaks. The detected peaks are then processed by four basic rules, as follows: $i$. when consecutive peaks have a time interval below $150 \mathrm{~ms}$, the one with smaller amplitude is eliminated; ii. when consecutive peaks have a time interval below $360 \mathrm{~ms}$ and the amplitude of the last peak is smaller than half the amplitude of the other peak, the last peak is considered a $\mathrm{T}$ wave; iii. The remaining peaks whose amplitude are above a hard threshold are considered QRS complex peaks; iv. If no peak is found in an interval below $1.5 x R-R$ (where $R-R$ is the average interval of consecutive QRS complex evaluated on nine consecutive QRS complexes) the detection threshold is halved, and a new search is performed. 
The QRS complex peak can either be positive ( $\mathrm{R}$ wave) or negative (S wave). A peak with opposite polarity found up to 5 milliseconds after an $\mathrm{R}$ wave or before an $\mathrm{S}$ wave is considered, respectively, an $\mathrm{S}$ or an $\mathrm{R}$ wave. From the QRS peak, a search for the onset and offset of the QRS complex is performed, backward in order to find the plateau of the PQ interval, and forwards until a decrease in the slope just after the $\mathrm{J}$ point is found.

Among ECG delineation points, the most difficult one to detect is the end of the $\mathrm{T}$ wave ( $T$ wave offset). Even experienced specialists

Table 1. All criteria for detection of left ventricle hypertrophy (LVH) used for estimation of the fusion score sorted from the highest area under the ROC curve (AUC), which p-value indicates difference between normal and LVH groups.

\begin{tabular}{|c|c|c|}
\hline Criteria & AUC & p-value \\
\hline$(R+S)_{\text {anyprecordiallear }}($ Grant, 1957) & 0.823 & $<0.001$ \\
\hline$\left(R_{I}+S_{I I I}\right)($ Gubner and Ungerleider, 1943) & 0.810 & $<0.001$ \\
\hline$(\text { largest } R \vee S)_{V 1-V 6} \times t_{Q R S}$ (Mazzaro et al., 2008) & 0.776 & $<0.001$ \\
\hline$R_{I}($ Gubner and Ungerleider, 1943) & 0.794 & $<0.001$ \\
\hline$R_{a v L}($ Sokolow and Lyon, 1949) & 0.798 & $<0.001$ \\
\hline$\left(R_{I}-S_{I}\right)+\left(S_{I I I}-R_{I I I}\right)($ Lewis, 1914) & 0.807 & $<0.001$ \\
\hline QRSarea $_{a v L}$ (this work) & 0.763 & $<0.005$ \\
\hline QRSarea $_{I}$ (this work) & 0.742 & $<0.005$ \\
\hline$S_{I I I}$ (Zago et al., 2015) & 0.770 & $<0.005$ \\
\hline$\sum_{\text {leads }} Q R S_{\text {peak }} \times$ width $_{Q R S} \quad$ (Molloy et al., 1992) & 0.701 & $<0.005$ \\
\hline QRSarea $_{V 1}($ this work) & 0.659 & $<0.01$ \\
\hline$\left(S_{V}+R_{V 5}\right)($ Sokolow and Lyon, 1949) & 0.666 & $<0.01$ \\
\hline$\left(R_{a V \mathrm{~L}}+S_{V 3}\right) \times$ width $_{Q R S}($ Molloy et al., 1992) & 0.702 & $<0.01$ \\
\hline Strain pattern (Roman et al., 1987) & $\mathrm{NA}^{*}$ & $<0.01$ \\
\hline$\sum_{\text {leads }} Q R S_{\text {peak }}$ (Siegel and Roberts, 1982) & 0.690 & $<0.01$ \\
\hline$S_{V 2}+R_{V 4 \text { ou V5 }}$ (Wolff, 1962) & 0.673 & 0.011 \\
\hline$S_{V 3}+R_{a V L}($ Casale et al., 1985) & 0.705 & 0.013 \\
\hline$S_{V 2}+R_{V 5 \text { or V6 }}($ Romhilt et al., 1969) & 0.663 & 0.017 \\
\hline QRSArea $_{I I I}$ (this work) & 0.685 & 0.018 \\
\hline$R_{V 3}$ (this work) & 0.702 & 0.019 \\
\hline$S_{V 1 \text { or } V 2}+R_{V 6}($ Grant, 1957) & 0.681 & 0.024 \\
\hline$R_{\text {precordial }}($ McPhie, 1958$)$ & 0.672 & 0.026 \\
\hline$R_{a V R}$ (this work) & 0.683 & 0.027 \\
\hline$S_{V 1}($ this work $)$ & 0.659 & 0.029 \\
\hline$R_{V 5}$ (Wilson et al., 1944) & 0.658 & 0.029 \\
\hline$R_{V 4}$ (this work) & 0.703 & 0.032 \\
\hline$S_{V 1 \text { or V2 }}+R_{V 5 \text { or V6 }}$ (Murphy et al., 1984) & 0.684 & 0.032 \\
\hline$S_{a V F}$ (this work) & 0.665 & 0.038 \\
\hline STarea $_{\max }$ (this work) & 0.662 & 0.040 \\
\hline STarea $_{I I}$ (this work) & 0.658 & 0.040 \\
\hline$S_{a V R}$ (this work) & 0.611 & 0.043 \\
\hline$T p_{I I}$ (this work) & 0.647 & 0.044 \\
\hline$(R+S)_{\text {any bipolar lead }}$ (Romhilt and Estes, 1968) & 0.659 & 0.049 \\
\hline
\end{tabular}


differ from each other when determining this point in an ECG record. Several algorithms have been proposed so far for this purpose (Martínez et al., 2004; Zhou et al., 2009; Zhou and Wei, 2011). A simple and accurate algorithm was chosen, as was developed in (Zhang et al., 2006), which is based on the area under the $\mathrm{T}$ wave.

The algorithm proposed by Zhang employs knowledge regarding the $\mathrm{T}$ wave morphology in order to find its end. The algorithm is based on the area $A[n]$ under the curve $s[n]$ in an interval of width $W$ (shorter than the T wave) ending in a sample after $n$. The area is given by

$$
A[n]=\sum_{k=n-W}^{n}(s[k]-s[n])
$$

Considering the correct $\mathrm{T}$ wave offset at $n_{3}$, it is noted that moving the offset candidate to the right, would result in the area being reduced. The same happens when moving the offset candidate to the left, i.e., the area $A[n]$ would be reduced, as it is shown in Figure 1.

We conclude that the maximum value of the area $A[n]$ occurs when $n=n_{3}$ which is the correct $\mathrm{T}$ wave offset. Similar algorithms are used to detect the wave offset in other T-wave morphologies, namely negative and biphasic $\mathrm{T}$ waves. Finally, this method is simple and robust to noise.

From the ECG segmentation, some features related to amplitudes and intervals are extracted from all 12-ECG leads. It is important to emphasize that included in the study are features from the R, S and T wave amplitude and duration, the area under the QRS complex, the QT interval and the interval between the $\mathrm{Q}$ wave and the $\mathrm{T}$ wave peak, the electrical axis and the strain pattern, besides the features already used so far by cardiologists (Hancock et al., 2009).
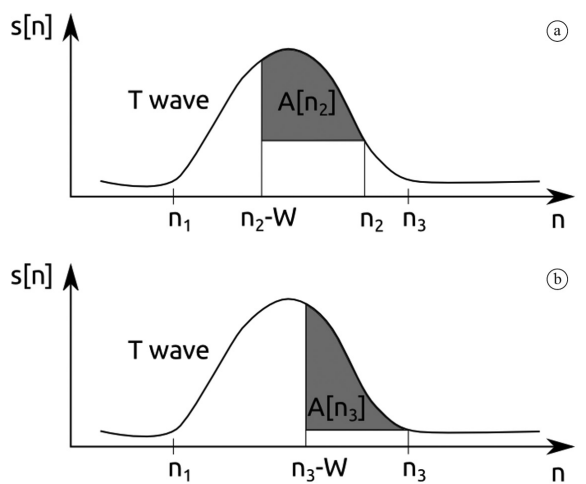

Figure 1. Illustration of Zhang's method. (a) shows $A[n]$ (the area between $\mathrm{s}[\mathrm{n}]$ and the signal from sample $\mathrm{n}-\mathrm{W}$ to $\mathrm{n}$ ) decreasing when the window is left of the correct $\mathrm{T}$ wave end point $n_{3}$. (b) shows $A[n]$ in its highest value. Modified from Zhang et al. 2006.
The extracted ECG features are then combined according to each LVH criteria. The whole set of criteria is shown in Table 1. Some selected criteria are summarized below:

- $(R+S)_{\text {anvprecordiallear }}($ Grant, 1957): the greatest sum of the $\mathrm{R}$ and $\mathrm{S}$ wave amplitudes among the precordial leads.

- $\left(R_{I}+S_{I I I}\right)$ (Gubner and Ungerleider, 1943): the sum of the $\mathrm{R}$ wave amplitude in lead I and the $\mathrm{S}$ wave amplitude in lead III.

- (largest $R \vee S)_{\text {anyprecordiallear }} \times t_{\text {QRS }}$ (Mazzaro et al., 2008): the highest $\mathrm{R}$ or $\mathrm{S}$ peaks among the precordial leads multiplied by the duration of the QRS complex in that lead.

- $\quad R_{I}$ (Gubner and Ungerleider, 1943): R wave amplitude in lead I.

- $\left(R_{I}-S_{I}\right)+\left(S_{I I I}-R_{I I I}\right)$ (Lewis, 1914): the sum of the difference between the $\mathrm{R}$ and $\mathrm{S}$ amplitudes in lead I, and the $\mathrm{S}$ and $\mathrm{R}$ amplitudes in lead III.

- $\quad R_{a v L}$ (Sokolow and Lyon, 1949): amplitude of $\mathrm{R}$ wave in lead avL.

- QRSarea $_{a v L}$ : the area under the QRS complex in lead avL.

- QRSarea: the area under the QRS complex in lead I.

- $S_{I I I}$ : amplitude of the $\mathrm{S}$ wave in lead III.

All criteria require a threshold which separates LVH and normal ECGs. For the new criterion proposed in this work, the threshold is determined with the help of a ROC curve, which is a technique to visualize, organize and select classifiers based on their performance (Fawcett, 2006). In this kind of two dimensional plot, the $\mathrm{Y}$ axis is the true positive rate (TPR) and the $\mathrm{X}$ axis is the false positive rate (FPR). Each point of a ROC curve is generated by selecting a certain magnitude of that feature to separate normal and LVH records. The resulted TPR and FPR are marked at the ROC curve. The magnitude which satisfies a false positive rate of $25 \%$ (specificity of $75 \%$ ) is chosen as the threshold. This step is not necessary for the criteria proposed in the literature because the thresholds are already defined. For example, we have the Sokolow index (Sokolow and Lyon, 1949) defining that every ECG with R in aVL greater than $11 \mathrm{~mm}$ should be classified as LVH.

\section{Score fusion}

Since the different criteria proposed so far are not good enough to detect LVH patients, we have proposed a score based on the most relevant criteria. 
The original method proposed in this paper consists of fusing the previously explained criteria and thereby generating a single score which is used to assess $\mathrm{LVH}$. The fusion strategy is described below.

1. The features of the ECG record are tested according to one of the 33 criteria. All the criteria indicating the presence of LVH are considered positive.

2. If an ECG has more than fourteen positive criteria, the patient is identified as LVH. This number of 14 positive criteria was found through the ROC curve considering FPR of $10 \%$.

Thus, the score is a number that represents the probability of LVH presence in a specific individual.

\section{Database}

The database used was a subset of the MONICA2 Database Project (2004/5) following the general guidelines of WHO MONICA Project, which was developed in order to determine the prevalence and severity of cardiovascular risk factors in the general population (25-64 years old) in Vitória, Brazil (Angelo et al., 2007; Pires de Sousa et al., 2009).

The study sample was chosen after a random selection of households in 1999, when 2068 subjects were invited to participate in the study, from a population of 142,913 people of both genders with ages ranging from 25 to 64 years. From the selected subjects, 1661 agreed to participate in the study and went to the Cassiano Antonio Moraes hospital in Vitória, Brazil, for clinical and laboratory examination so as to determine prevalence of cardiovascular risk factors. In 2004-5, 652 participants were re-examined to repeat the clinical and laboratory exams and to obtain a new ECG and echocardiogram records (Angelo et al., 2007; Pires de Sousa et al., 2009).
A subsample of this cohort was selected after the second examination to generate a sample of normal subjects. The echocardiographic data from these healthy subjects were used to generate reference values for cardiac structure and function (Angelo et al., 2007), including LVMI. The results showed that the upper limit for the LVMI (defined by the $95 \%$ percentile) was:

- $\quad$ LVMI $=46.6 \mathrm{~g} / \mathrm{m}^{2.7}$ for the complete subset;

- $\quad$ LVMI $=46.4 \mathrm{~g} / \mathrm{m}^{2.7}$ for the female subset;

- $\quad$ LVMI $=47.7 \mathrm{~g} / \mathrm{m}^{2.7}$ for the male subset.

Thus, individuals with LVMI below these values can be considered as having a normal LVMI. The subset used in this study was composed by 50 male subjects without any kind of change in the conventional 12-lead ECG record. From the databank 25 subjects were selected with LVMI larger than 47.7 and 25 subjects with LVMI smaller than this cut off. The subjects were randomly selected following the requirement that the age distribution of the two groups should be close in order to avoid any influence derived from age on the analysis. The demographic and clinical baseline characteristics of the selected subjects are shown in Table 2.

\section{Results}

First of all, the performance of each LVH criterion was separately assessed, as follows:

1. ROC curve: Employing the ROC curve method, it was possible to analyze the cost (false positive rate, also shown as 1 -specificity) and the benefit (true positive rate or sensibility) of the classifier. An example of a ROC curve is shown in Figure 2.

2. Hypothesis test for separable groups: A paired t-test was performed so as to test the null hypothesis that the difference between

Table 2. Demographic and clinical characteristics of individuals with normal left ventricle mass index (LVMI) and increased LVMI. Each variable is presented as mean and standard deviation (SD).

\begin{tabular}{lcc}
\hline & Normal LVMI & Increased LVMI \\
& Mean (SD) & $59.3(9.0)$ \\
\hline Age (years) & $58.6(10.0)$ & $153(24)$ \\
Systolic blood pressure (mm Hg) & $138(18)$ & $96(16)$ \\
Diastolic blood Pressure (mm Hg) & $91(10)$ & $98(15)$ \\
Glucose (mg/dl) & $103(30)$ & $1.2(0.3)$ \\
Creatinine (mg/dl) & $1.1(0.3)$ & $29.1(8.9)$ \\
Urea (mg/dl) & $31.5(8.8)$ & $201(44)$ \\
Total cholesterol (mg/dl) & $191(34)$ & $41(8)$ \\
High density lipoprotein (HDL) cholesterol (mg/dl) & $43(10)$ & $27.4(3.2)$ \\
Body mass index (kg/m2) & $25.8(3.5)$ & $61.8(9.9)$ \\
LVMI (g/m 2.7 ) & $37.8(6.1)$ & \\
\hline
\end{tabular}


the normal and the LVH groups ( $\mathrm{y}-\mathrm{x})$ is a zero-mean normal distribution. If the hypothesis was accepted with significance level of $5 \%$, the groups were non-separable.

Table 1 shows the results of the area under the ROC curve (AUC), as well as the p-value for the hypothesis test for separable groups. It was observed that the best criteria for group separation were those related to the QRS amplitude or duration. Thus, it is clear that LVH causes more changes in the QRS complex than in other ECG waves. It is also evident that the features with lower p-value have higher AUC, showing that they are good for group separation, as was expected.

Thirty three different criteria were tested, employing the features discussed in the previous section.

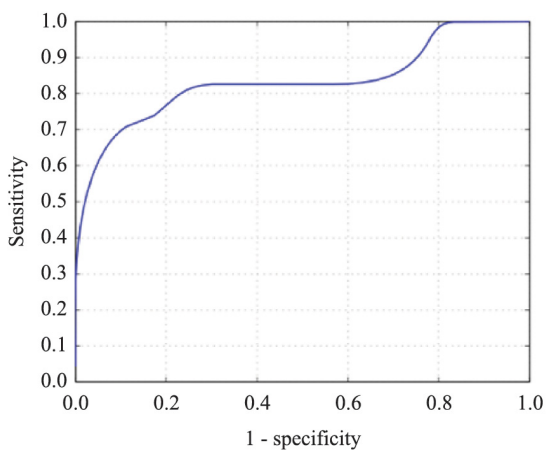

Figure 2. ROC curve for the method proposed in Grant (1957).
Considering all the tested criteria, the score fusion for LVH classification was performed. The score fusion method can be configured according to a sensibility or specificity goal. In this article, two different goals were selected: high sensitivity or high specificity. Our results regarding the score fusion are presented in Table 3, together with the results obtained by other studies on this subject. It is worth mentioning that all the methods were implemented and tested in the same database.

From Table 3, the observation was that the fusion score developed here improves sensitivity and specificity, achieving a specificity of $91.30 \%$ and sensitivity of $78.26 \%$, this being higher than other proposed methods in the literature so far.

The selected methods were also compared to the LVMI in terms of the Pearson correlation coefficient and p-value, which are shown in Table 4. The results are consistent with the one from Table 3 , except for the method proposed by Gubner and Ungerleider (1943).

\section{Discussion}

In this article, a score for LVH classification was tested in 12-lead ECG records from a population sample. Our experiments considered different LVH criteria, most of them based on ECG features. The gold standard for LVH classification was the mass of the left ventricle obtained by echocardiographic examination, indexed to patient height raised to the power of $2.7\left(n^{2.7}\right)$.

Table 3. Performance for left ventricle hypertrophy detection using several criteria. The table shows the sensitivity (Se), the specificity (Sp) and accuracy of each method.

\begin{tabular}{lccc}
\hline & Se (\%) & Sp (\%) & Accuracy (\%) \\
\hline$(R+S)_{\text {anyprecordiallear }}($ Grant, 1957) & 56.52 & 95.65 & 76.09 \\
$\left(R_{I}+S_{I I I}\right)($ Gubner and Ungerleider, 1943) & 65.22 & 86.96 & 76.09 \\
$(\text { largest } R \vee S)_{V 1-V 6} \times t_{Q R S}($ Mazzaro et al., 2008) & 69.57 & 86.96 & 78.26 \\
$R_{I}($ Gubner and Ungerleider, 1943) & 82.61 & 73.91 & 78.26 \\
$\left(R_{I}-S_{I}\right)+\left(S_{I I I}-R_{I I I}\right)($ Lewis, 1914) & 73.91 & 82.61 & 78.26 \\
Fusion Score & 78.26 & 91.30 & 84.78 \\
\hline
\end{tabular}

Table 4. Pearson correlation coefficient (r) and p-value between selected left ventricle hypertrophy criteria and left ventricle mass index.

\begin{tabular}{lcc}
\hline \multicolumn{1}{c}{ Method } & r & p-value \\
\hline$(R+S)_{\text {anyprecordiallear }}($ Grant, 1957) & 0.382 & 0.001 \\
$\left(R_{I}+S_{I I I}\right)($ Gubner and Ungerleider, 1943) & 0.525 & $<0.0001$ \\
$(\text { largest } R \vee S)_{V 1-V 6} \times t_{Q R S}$ (Mazzaro et al., 2008) & 0.337 & 0.005 \\
$R_{I}($ Gubner and Ungerleider, 1943) & 0.448 & 0.0001 \\
$\left(R_{I}-S_{I}\right)+\left(S_{I I I}-R_{I I I}\right)$ (Lewis, 1914) & 0.537 & $<0.0001$ \\
Fusion Score & 0.627 & $<0.0001$ \\
\hline
\end{tabular}


The results pointed out that the features that best correlate with LVMI are those related to the QRS complex amplitude and duration. Moreover, the present study proposes a score based on a combination of results from several criteria, some of them proposed in the literature and others originally proposed in this paper, all of them fully automatic calculated.

In order to test for inter-lead features (e.g. QT dispersion) we had to use a 12-lead database that also contained echocardiography exams. Because of the strict selection rules for this study only a few records from the database could be used.

The performance of the fusion score proposed in this study was greater than the criteria used by experts, with specificity and sensitivity equal to $91.3 \%$ and $78.3 \%$, respectively. Unlike the other methods, our score must be estimated with in a computer because of its high complexity. Even with this limitation it is much less expensive than using the echocardiograph which is an expensive exam.

Improvements can be achieved when this work is reproduced on a large database. In addition to increasing the scientific significance, automatic classification methods that require a greater number of records to split between training and testing sets may be used. Regarding future works, the plan is to test the proposed score in a larger database in order to confirm the consistency of these results.

\section{Acknowledgements}

We thank CAPES (Brazilian Ministry of Education) and $\mathrm{CNPq}$ for providing financial support and the federal institute of Espírito Santo for providing the English revision of the paper.

\section{References}

Angelo LCS, Vieira MLC, Rodrigues SL, Morelato RL, Pereira AC, Mill JG, Krieger JE. Echocardiographic reference values in a sample of asymptomatic adult Brazilian population. Arquivos Brasileiros de Cardiologia. 2007; 89(3):168-73, 184-90. PMid:17906818.

Casale PN, Devereux RB, Kligfield P, Eisenberg RR, Miller DH, Chaudhary BS, Phillips MC. Electrocardiographic detection of left ventricular hypertrophy: development and prospective validation of improved criteria. Journal of the American College of Cardiology. 1985; 6(3):572-80. http:// dx.doi.org/10.1016/S0735-1097(85)80115-7. PMid:3161926.

De Simone G, Kizer JR, Chinali M, Roman MJ, Bella JN, Best LG, Lee ET, Devereux RB, Strong Heart Study Investigators. Normalization for body size and populationattributable risk of left ventricular hypertrophy: the Strong Heart Study. American Journal of Hypertension. 2005; 18(2 Pt 1):191-6. http://dx.doi.org/10.1016/j.amjhyper.2004.08.032. PMid:15752946.
Devereux RB, Alonso DR, Lutas EM, Gottlieb GJ, Campo E, Sachs I, Reichek N. Echocardiographic assessment of left ventricular hypertrophy: comparison to necropsy findings. The American Journal of Cardiology. 1986; 57(6):450-8. http:// dx.doi.org/10.1016/0002-9149(86)90771-X. PMid:2936235.

Fawcett T. An introduction to ROC analysis. Pattern Recognition Letters. 2006; 27(8):861-74. http://dx.doi. org/10.1016/j.patrec.2005.10.010.

Ganau A, Devereux RB, Roman MJ, Simone G, Pickering TG, Saba PS, Vargiu P, Simongini I, Laragh JH. Patterns of left ventricular hypertrophy and geometric remodeling in essential hypertension. Journal of the American College of Cardiology. 1992; 19(7):1550-8. http://dx.doi.org/10.1016/07351097(92)90617-V. PMid:1534335.

Grant RP. Clinical electrocardiography: the spatial vector approach. New York: McGraw-Hill Book Company; 1957.

Gubner R, Ungerleider HE. Electrocardiographic criteria of left ventricular hypertrophy. Archives of Internal Medicine. 1943; 72(2):196-209. http://dx.doi.org/10.1001/ archinte.1943.00210080052005.

Haider AW, Larson MG, Benjamin EJ, Levy D. Increased left ventricular mass and hypertrophy are associated with increased risk for sudden death. Journal of the American College of Cardiology. 1998; 32(5):1454-9. http://dx.doi. org/10.1016/S0735-1097(98)00407-0. PMid:9809962.

Hamilton P. Open source ECG analysis. Computers in Cardiology. 2002; 29:101-4.

Hancock EW, Deal BJ, Mirvis DM, Okin P, Kligfield P, Gettes LS, Bailey JJ, Childers R, Gorgels A, Josephson M, Kors JA, Macfarlane P, Mason JW, Pahlm O, Rautaharju PM, Surawicz B, van Herpen G, Wagner GS, Wellens $\mathrm{H}$, American Heart Association Electrocardiography and Arrhythmias Committee, Council on Clinical Cardiology, American College of Cardiology Foundation, Heart Rhythm Society, Endorsed by the International Society for Computerized Electrocardiology. AHA/ACCF/HRS recommendations for the standardization and interpretation of the electrocardiogram: part V: electrocardiogram changes associated with cardiac chamber hypertrophy: a scientific statement from the American Heart Association Electrocardiography and Arrhythmias Committee, Council on Clinical Cardiology; the American College of Cardiology Foundation; and the Heart Rhythm Society. Journal of the American College of Cardiology. 2009; 53(11):992-1002. http://dx.doi.org/10.1016/j.jacc.2008.12.015. PMid:19281932.

Kreger BE, Cupples LA, Kannel WB. The electrocardiogram in prediction of sudden death: framingham study experience. American Heart Journal. 1987; 113(2 Pt 1):377-82. http:// dx.doi.org/10.1016/0002-8703(87)90281-X.

Lewis T. Observations upon ventricular hypertrophy with especial reference preponderance of one or other chamber. Heart. 1914; 5:367-403.

Martínez JP, Almeida R, Olmos S, Rocha AP, Laguna P. A wavelet-based ECG delineator: evaluation on standard databases. IEEE Transactions on Biomedical Engineering. 2004; 51(4):570-81. http://dx.doi.org/10.1109/TBME.2003.821031. PMid: 15072211 . 
Mazzaro CDL, Costa FDA, Bombig MTN, Luna B Fo, Paola ÂAV, Carvalho ACDC, Costa W, Fonseca FAH, Póvoa RMDS. Ventricular mass and electrocardiographic criteria of hypertrophy: evaluation of new score. Arquivos Brasileiros de Cardiologia. 2008; 90(4):227-31, 249-253.

McPHIE J. Left ventricular hypertrophy: electrocardiographic diagnosis. Australasian Annals of Medicine. 1958; 7(4):31727. PMid:13607332.

Molloy TJ, Okin PM, Devereux RB, Kligfield P. Electrocardiographic detection of left ventricular hypertrophy by the simple QRS voltage-duration product. Journal of the American College of Cardiology. 1992; 20(5):1180-6. http:// dx.doi.org/10.1016/0735-1097(92)90376-X. PMid:1401620.

Murphy ML, Thenabadu PN, Soyza N, Doherty JE, Meade J, Baker BJ, Whittle JL. Reevaluation of electrocardiographic criteria for left, right and combined cardiac ventricular hypertrophy. The American Journal of Cardiology. 1984; 53(8):1140-7. http://dx.doi.org/10.1016/0002-9149(84)906519. PMid:6230928.

Roman MJ, Kligfield P, Devereux RB, Niles NW, Hochreiter C, Halle A, Sato N, Borer JS. Geometric and functional correlates of electrocardiographic repolarization and voltage abnormalities in aortic regurgitation. Journal of the American College of Cardiology. 1987; 9(3):500-8. http:// dx.doi.org/10.1016/S0735-1097(87)80041-4. PMid:3819197.

Romhilt DW, Estes EH Jr. A point-score system for the ECG diagnosis of left ventricular hypertrophy. American Heart Journal. 1968; 75(6):752-8. http://dx.doi.org/10.1016/00028703(68)90035-5. PMid:4231231.

Romhilt DW, Bove KE, Norris RJ, Conyers E, Conradi S, Rowlands DT, Scott RC. A critical appraisal of the electrocardiographic criteria for the diagnosis of left ventricular hypertrophy. Circulation. 1969; 40(2):185-96. http://dx.doi.org/10.1161/01.CIR.40.2.185. PMid:4240354.

Siegel RJ, Roberts WC. Electrocardiographic observations in severe aortic valve stenosis: correlative necropsy study to clinical, hemodynamic, and ECG variables demonstrating relation of 12-lead QRS amplitude to peak systolic transaortic pressure gradient. American Heart Journal. 1982; 103(2):21021. http://dx.doi.org/10.1016/0002-8703(82)90494-X. PMid:6459734.

Sokolow M, Lyon TP. The ventricular complex in left ventricular hypertrophy as obtained by unipolar precordial and limb leads. American Heart Journal. 1949; 37(2):16186. http://dx.doi.org/10.1016/0002-8703(49)90562-1. PMid:18107386.

Sousa AGP, Pereira AC, Marquezine GF, Nascimento-Neto RM, Freitas SN, Nicolato RLC, Machado-Coelho GL, Rodrigues SL, Mill JG, Krieger JE. Derivation and external validation of a simple prediction model for the diagnosis of type 2 diabetes mellitus in the Brazilian urban population. European Journal of Epidemiology. 2009; 24(2):101-9. http:// dx.doi.org/10.1007/s10654-009-9314-2. PMid:19190989.

Wilson FN, Johnston FD, Rosenbaum FF, Erlanger H, Kossmann CE, Hecht H, Cotrim N, Oliveira RM, Scarsi $\mathrm{R}$, Barker PS. The precordial electrocardiogram. American Heart Journal. 1944; 27(1):19-85. http://dx.doi.org/10.1016/ S0002-8703(44)90603-4. PMid:20996759.

Wolff MDL. Electrocardiography: fundamentals and clinical applications. St. Louis: W.B. Saunders; 1962.

Zhang Q, Manriquez AI, Médigue C, Papelier Y, Sorine M. An algorithm for robust and efficient location of T-wave ends in electrocardiograms. IEEE Transactions on Biomedical Engineering. 2006; 53(12 Pt 1):2544-52. http://dx.doi. org/10.1109/TBME.2006.884644. PMid:17153212.

Zhou SH, Helfenbein ED, Lindauer JM, Gregg RE, Feild DQ. Philips QT interval measurement algorithms for diagnostic, ambulatory, and patient monitoring ECG applications. Annals of Noninvasive Electrocardiology. 2009; 14(Suppl 1):S3-8. http://dx.doi.org/10.1111/j.1542474X.2008.00258.x. PMid:19143739.

Zhou X, Wei D. A multidifferentiator-based approach to the reliable determination of T-wave offset in electrocardiograms. Journal of Electrocardiology. 2011; 44(3):330-9. http://dx.doi. org/10.1016/j.jelectrocard.2010.11.003. PMid:21276591.

\footnotetext{
Authors

Gabriel Tozatto Zago ${ }^{*}$, Rodrigo Varejão Andreão², Sérgio Lamego Rodrigues ${ }^{3}$, José Geraldo Mill Mário Sarcinelli Filho ${ }^{4}$

${ }^{1}$ Departamento de Automação Industrial, Instituto Federal do Espírito Santo - IFES, Serra, ES, Brazil.

${ }^{2}$ Departamento de Engenharia Elétrica, Instituto Federal do Espírito Santo - IFES, Vitória, ES, Brazil.

${ }^{3}$ Programa de Pós-Graduação em Ciências Fisiológicas, Universidade Federal do Espírito Santo - UFES, Vitória, ES, Brazil.

${ }^{4}$ Programa de Pós-Graduação em Engenharia Elétrica, Universidade Federal do Espírito Santo - UFES, Vitória, ES, Brazil.
} 